\title{
Toward Reflexive Climate Adaptation Research
}

Benjamin L. Preston ${ }^{1,2^{*}}$

Lauren Rickards ${ }^{3}$

Hartmut Fünfgeld ${ }^{3}$

Rodney J. Keenan ${ }^{4}$

${ }^{1}$ Climate Change Science Institute, Oak Ridge National Laboratory

${ }^{2}$ Environmental Sciences Division, Oak Ridge National Laboratory

${ }^{3}$ Global, Urban, and Social Studies, RMIT University

${ }^{4}$ School of Ecosystem and Forest Sciences, University of Melbourne

*Corresponding Author

Climate Change Science Institute and Environmental Sciences Division

Oak Ridge National Laboratory

Building 2040, Room E239, MS-6301

PO Box 2008

One Bethel Valley Road

Oak Ridge, TN 37831-6253

Phone: +1 8654566531

Email: prestonbl@ornl.gov

17 April, 2015 


$\begin{array}{ll}1 & \text { Abstract } \\ 2 & \text { Climate adaptation research is expanding rapidly within an increasingly reflexive society } \\ 3 & \text { where the relationship between academia and other social institutions is in a state of flux. } \\ 4 & \text { Tensions exist between the two dominant research orientations of research about and research } \\ 5 & \text { for adaptation. In particular, the research community is challenged to develop processes for } \\ 6 & \text { successfully executing transdisciplinary research for adaptation when academic institutions } \\ 7 & \text { and researchers are largely structured around traditional, disciplinary expertise and funding } \\ 8 & \text { models. One tool for helping to manage this tension is a third, more reflexive, orientation } \\ 9 & \text { toward adaptation research that is emerging in the literature. This new 'research on adaptation } \\ 10 & \text { research' promises to help enhance understanding of the research enterprise itself and how it } \\ 11 & \text { can become more adaptive. }\end{array}$




\section{Introduction}

The climate adaptation research enterprise has grown markedly over the past decade as evidenced by exponential growth in research publications (Figure 1), new research institutions dedicated to adaptation [1], and the emergence of adaptation science as a research discipline [2]. This rapid growth has occurred within a broader dynamic of increasingly blurred boundaries between social institutions of academia, government, business, and legal systems[3]. This contributes to a range of epistemological, methodological and practical challenges and tensions for adaptation researcher and researchers. Such tensions arise from the multiple orientations of adaptation research, at least two of which are now well-documented in the literature [1,2]. The first is research about adaptation, which emphasizes fundamental understanding of adaptation processes in human and natural systems, without necessarily seeking to inform or facilitate a particular adaptation response. The second is research for adaptation, which is more applied in nature as it attempts to generate knowledge that identifies adaptation options, supports adaptation planning, and guides implementation processes. These two different orientations reflect fundamentally different perspectives with respect to the function of adaptation research within society [4-6].

Left to co-exist as parallel endeavors, these two orientations lead to tensions that adaptation researchers must negotiate. These can be explored in the context of Cash et al.'s three oft-cited knowledge criteria for linking science to policy: salience, credibility, and legitimacy [7]. Researchers must select their preference for research about versus for adaptation, which ultimately is a preference regarding the balance between credibility (directing effort towards the development of fundamental knowledge and academic indicators of merit) and relevance (directing effort at generating observable societal benefits). Research credibility is needed in light of the complexity and associated uncertainty of climate change, its consequences, and the planning and implementation of adaptation responses. Where such issues of credibility are emphasized, researchers are inclined to shy away from speaking directly to the policy implications of their research. Yet, practitioners and research stakeholders often seek directive statements and clear, practical, evidence-based adaptation solutions. Furthermore, research based on the perceived needs of stakeholders can lead to tensions regarding the legitimacy of knowledge and subsequent policy preferences [8]. In practice, adaptation may involve multiple stakeholders with their own needs, values, and preferences that influence the manner in which research is framed and executed. 
While significant attention has been devoted to how to best use climate change science to facilitate adaptation, these tensions are not well-appreciated [9-13], in part due to an emphasis on the research rather than on the researcher. Yet, they have important consequences with respect to the development of successful adaptation research endeavors and, subsequently, robust adaptation practice. Hence, there is an emergent third orientation in adaptation research that targets the research paradigm itself and the role of the researcher within it. This research on adaptation research represents a reflexive approach toward adaptation research and its role in generating knowledge for adaptation planning, policy, and implementation. Considered a route to enhanced adaptive capacity [14] and effective governance under climate change $[15,16]$, reflexivity is about the development of a research enterprise that is responsive to learning and critically reflective of not only what a researcher is doing, but, as popularized by Schön [17] and Cunliffe [18] with their notion of the 'reflexive practitioner,' why, how, and to what effect.

This paper reviews literature on the institutional, epistemic, and interpersonal challenges of conducting adaptation research, beginning with the broad science-policy context. The objective is to articulate the plight of adaptation researchers engaged in generating credible, salient, and legitimate adaptation knowledge within an "institutional void" [19] characterized by diverse and, at times, conflicting expectations and objectives for their research. In addition, this paper seeks to illustrate the manner in which reflexive thinking is increasingly driving critical analysis of the adaptation research process, its links to adaptation practice, and what it means to be an adaptation researcher.

\section{Adaptation Research and the Evolving Science Polity}

The growth in adaptation research has coincided with a marked shift in the science polity - the institutional structures in which adaptation science, and the scientific enterprise more broadly, take place. While funding bodies for scientific research have often sought national or international benefits from their investments, there is increasing demand for a clear line of sight between research investment and evidence of its economic, societal or environmental returns. This has translated into a greater emphasis on problem-oriented, rather than curiosity-driven, research. Multiple authors have labelled this phenomenon the 'corporatization' of academia due to the enhanced emphasis on market-based principles (such as cost effectiveness and return on investment), impact metrics, competition, training of students for post-graduate occupations, and the growing involvement of the private sector with institutions of higher learning [20-24]. 
In essence, this reflects a shift with respect to the role of higher learning in society and, subsequently, an erosion of the boundaries among the institutions of academia, government, and private businesses. It has also led to the framing of adaptation research around a knowledge deficit paradigm, [25] whereby understanding of the risks posed by climate change and the development of appropriate responses are contingent upon scientific knowledge [26]. As a case-in-point, the Australian Government has characterized investments in climate change science as ". . .the essential system knowledge without which adaptation strategies and mitigation strategies cannot readily be built. . .” [27, pg. 7]. Investments in research are valued in the context of their utility for policy development and/or as stimuli for economic development.

The corporatization of science is symptomatic, however, of larger social transitions analogous to those articulated in the theory of reflexive modernization [26,28-31]. Key elements reflexive modernization are a) the erosion of the power of state actors and of the boundaries between traditional social institutions $[19,26,30]$; b) increased politicization of science and the reduced value placed on disciplinary, scientific expertise [19]; and c) an increased role of civil society in deliberations regarding risk [26,28]. In this context, the growing emphasis on adaptation research reflects the increasing importance of scientific knowledge to adaptation planning and implementation. The institutional integration of academia, government, and private interests in pursuit of research for adaptation is indicative of the blurring of institutional boundaries. Meanwhile, the increasing participation of stakeholders with non-scientific expertise in adaptation research reflects the democratization of climate risk management and the increasing role of normative positions in adaptation research. Climate change science and adaptation research signify a more reflexive attitude towards modernization, as they involve efforts to understand and address a major problem (i.e., anthropogenic climate change) generated by the preceding wave of industrial modernization. Meanwhile, resistance to scientific findings regarding climate change and/or policy prescriptions for reducing climate risk reflects perceptions of beneficiaries of the first wave of modernity that they could lose out in an increasingly reflexive world [32].

The more porous boundaries between academia and other social institutions in this more reflexive world has created a requirement for researchers to be more responsive to the knowledge needs of others, including elected officials and staff in various levels of government as well as corporate decision-makers and other beneficiaries [33-37]. For some researchers and practitioners, this involves selectively, rapidly, and assertively filling general adaptation knowledge deficits [25], as reflected in ongoing calls for researchers to provide 
and disseminate clear and accessible knowledge about climate change, its consequences, and adaptation responses [33-37]. This puts some researchers in the role of 'science arbiters' [38] who provide expertise on scientific (i.e., positive) questions, but avoid normative issues inherent in policy and decision-making. This redoubling of effort in communicating climate change science has been partly fuelled by the desire to redress the explicit or implicit inaction on such knowledge to date by some members of society, including senior decision-makers [39], as well as growing recognition that adaptation is not infinite or a guaranteed panacea [40].

For others the tighter link between academia and society reflects a deeper shift toward not just communicating knowledge, but directly addressing the practical problems facing decision-makers and providing tailored, fit-for-purpose knowledge [41]. This positions researchers as 'honest brokers' [42] of scientific knowledge that that can be integrated into decision-making processes in order to collectively identify, analyze, and expand policy alternatives. In so doing, researcher must appreciate the way adaptation options and their implementation are shaped by social and political factors, whether those common to policy and practice or those triggered in particular by the uncertain, normative, and political nature of adaptation [33,43-45]. Knowledge in such a context becomes an ongoing negotiation as questions of how, why, who, and when merge with the question of what to do, and the boundaries between research and doing, and knowing and learning, blur. As discussed further below, this means research often actively involves stakeholders in the co-production of knowledge [46].

Whether providing new general information or helping to design tailored solutions, research organizations and researchers have increasingly begun to a) position themselves as adaptation service providers; b) engage more directly with a broad array of clients in both the public and private sector to align research outputs with knowledge needs; and c) establish new research funding mechanisms and organizational structures at the boundary of science and policy [1,47-49]. A common objective of such activities is to cultivate science translators to improve the perceived relevance and legitimacy of knowledge production, or, more abstractly, to facilitate the simultaneous production of "mutually supporting forms of knowledge and forms of life" [50, pg. 397]. Nevertheless, because such knowledge coproduction partnerships, and problem-oriented research more generally, represent a departure from the long-standing and still dominant traditional research models involving investigatorled project development and competitive funding, they present challenges for research funding bodies, research managers, and individual researchers [1]. The institutional 
dynamism and flux associated with reflexive modernization reflects an adaptation to social change, but the transition is disruptive and therefore contributes to tensions as researchers and the beneficiaries of research renegotiate social norms and institutional roles regarding research and its use.

\section{Tensions in the Production of Adaptation Knowledge}

Recent literature has identified a number of practical challenges for adaptation research within this evolving institutional landscape $[1,51,52]$. However, for those acting as 'pure scientists' [38] in pursuit of research about adaptation, adhering to a traditional, fundamental research paradigm would seem to limit exposure to the institutional complexities of more applied research. Yet, even pure scientists are increasingly tasked with articulating the societal benefits of their proposed research. The U.S. National Science Foundation includes "benefits to society" as a review criterion [53], while Australia's Research Council's conceptual model of the research impact pathway includes job creation, policy integration, and commercialization as research outcomes [54]. This puts pressure on adaptation researchers to identify pathways by which their research can inform adaptation practice and outcomes. Hence, research about adaptation may be framed as research for adaptation as researchers adapt to the evolving expectations and incentives of research funding bodies. This raises potential problems. For example, literature reviews of vulnerability assessments have found that while decision-support is often stated as research goal, more often than not, stakeholders are not identified or engaged $[55,56]$. If research execution does not follow a pathway that leads to societal impact, and/or if researchers are not rewarded for their efforts, a disconnect can emerge between society's demand for salient knowledge and academia's capacity to deliver.

Research that is explicitly for adaptation faces more extensive challenges that are associated with the integration of science and decision-making [57-59]. The growing demand for policy-relevant adaptation knowledge is being sought from an academic culture that remains centered on traditional disciplines with strong epistemological affinity, often built around hypothesis-driven experimentation $[52,60]$. Researchers are generally trained and credentialed in a specific discipline. Yet, research for adaptation often explicitly involves non-academic stakeholders in the research process [61, pg. 866,62] with the understanding that they possess critical expertise and perspectives regarding what knowledge is relevant and how knowledge is linked to decision-making processes [e.g., 63]. Such transdisciplinary 
research relies on individuals trained in different disciplines joining forces and working towards more integrated, co-produced forms of adaptation knowledge. To be effective in such research environments, researchers require a range of complementary skills: communication skills that are effective across different actors; procedural, facilitation, and management skills; as well as a certain degree of humility to recognize the limitations of one's own knowledge and openness to other systems of thought [64]. However, these are not necessarily skills that are routinely cultivated during the process of disciplinary training received by most researchers. Transdisciplinary adaptation research requires time to enable deliberation among participants $[58,65,66]$; and timing to pair research activities to a receptive policy environment. Research may require, and be evaluated upon, non-traditional outputs including practice oriented texts (e.g., webpages, policy briefs, and media articles) or new policy initiatives and their implementation. These outputs may be difficult to reconcile with traditional academic metrics of success, such as peer-reviewed articles in academic journals.

Transdisciplinary adaptation research can put further demands on researchers above and beyond the traditional research process per se [1], as researchers have to play multiple roles [67]. Returning to Cash et al.'s [7] criteria, researchers are expected to pursue research credibility by the nature of their disciplinary expertise; pursue salience by recognizing the complexities of policy environments; and pursue legitimacy through stakeholder engagement and acting as a general intermediary among different types of knowledge [68,69]. Playing these roles well requires effort in building the required knowledge and relationships, yet such work is often unrecognized and unpaid [70]. Routine tasks like setting up contracts and budgetary flows can be strongly hampered by existing systems and politics [71] that are poorly structured to enable cooperation among diverse institutions. Meanwhile, non-human elements of research such as contracts, reports, and physical office locations can influence knowledge production. For example, Ayre and Nettle [72] highlight the material, textual, and social devices or practices that shaped the knowledge integration in their large project on a large river catchment in Australia. Because navigating these various challenges and sensitivities is fundamental to transdisciplinary research, the associated effort should be explicitly integrated into research funding, design, execution, and evaluation.

Overall, in adaptation “. . . scientists no longer 'only' analyze sustainability issues, but, rather, need to immerse themselves into decision processes that are embedded in societal transition processes and build socially robust knowledge - with necessary changes in research modes, incentive structures, and reward systems" [73, pg. 7]. While researchers 
know that only a fraction of their time is spent actually undertaking research, they are also increasingly cognizant of the additional, but necessary, burdens of para-research labor associated with transdisciplinary research. Poor recognition of the practical resource and procedural demands of effective transdisciplinary research may leave research efforts underscoped and under-resourced with respect to financial, human, and social capital.

\section{Toward Reflexive Adaptation Research and Practice}

The practical challenges associated with the adaptation research enterprise in the current era of institutional flux suggest the need for greater understanding of such research in itself. Given this, we argue that in addition to research about and for adaptation, a third orientation is needed: reflexive adaptation research - research on adaptation research. The purpose of this orientation is to critically reflect upon the broad direction of adaptation research, including its ongoing institutionalization and implementation [e.g., 16,74,75], in order to enhance reflexivity about the implications for research organization, philosophy, politics, practice, and researcher roles $[1,2,76-80]$. This includes, for example, reflection on institutional mechanisms by which research needs are identified and funded; the processes and methods by which adaptation research is executed; and the mechanisms for evaluating research and researchers [16]. Such reflexive work requires focusing on the role of the researcher, in contrast to the practice-centric perspective of research for adaptation or the knowledgecentric perspective of research about adaptation. In other words, reflexivity focuses on the ways in which researchers' normative perspectives and experiences influence research findings, the manifestation of accepted knowledge, and the identification of new research directions $[1,81]$. In so doing, it can lead to the inclusion of a broader range of perspectives and forms of knowledge in adaptation research that can ultimately enhance the usefulness of research [16]. A reflexive orientation also brings adaptation research into contact with valuable sociological and institutional research on higher education, including long-standing insights about the tensions between unconventional research and dominant organizational factors [e.g., 82].

The adaptation literature contains a number of critiques that reflect the emergence of reflexivity in that they address the translational challenges of how adaptation research can be used in practice as well as issues around how knowledge is generated and its implicit assumptions (Table 1). At the most fundamental level is the apparent need for a more robust institutional framework for conducting adaptation research [83]. Other studies have raised 
questions regarding the adequacy of research approaches, methods, and tools for achieving adaptation outcomes. Research has emphasized not only that the manner in which researchers and practitioners frame adaptation influences process and outcome [84,85], but also that cognitive biases in framing may lead to spurious perceptions of risk, inappropriate responses, and/or misunderstanding of the institutional arrangements needed to implement those responses [86,87]. Studies have identified potential weaknesses in organizational adaptation planning as well as in understanding of which frameworks, methods, and tools should be applied to address different adaptation needs [88-90]. Metrics to measure vulnerability and risk in order to prioritize adaptation investments have been criticized on grounds of questionable credibility, salience, and legitimacy [55,91]. Meanwhile, metrics for tracking adaptation outcomes and success criteria have yet to be identified [92]. Research and practice are revealing that rather than adaptation being an inherent benefit that will be implemented optimally, adaptation can involve significant trade-offs and externalities [33,93-96]. Hence, there is a significant normative element to the pursuit of adaptation objectives that raises questions regarding how such decisions can be made in socially legitimate ways. Finally, various studies have pointed to both strengths and weaknesses of participation by stakeholders in adaptation research [97-99], as well as the need to incorporate ethical considerations in research processes $[100,101]$.

These examples highlight not only broader challenges associated with how adaptation is attempting to address climate change, but also with how adaptation research and the knowledge generated are being pursued and applied in addressing these challenges (Table 1). This more reflexive orientation toward adaptation research can contribute to more robust foundations for both research and practice. Preston et al. [87, pg. 482] argue that "the limitations or even failures of applied adaptation science eventually become evident leading to more critical appraisal of research methods." This highlights the need for greater scrutiny of both adaptation processes in practice as well as the processes of adaptation research that are assumed to inform that practice. The research community is increasingly willing to identify potential shortcomings and/or limitations in existing methods, metrics, and tools for adaptation (Table 1). As a consequence, adaptation research is likely to continue to evolve in response to learning about the relationship between research, practice, and outcomes. This will likely include continued experimentation and evolution with new ways of funding research; new ways of training adaptation researchers; new organizations to help manage the tensions arising from the shifting institutional arrangements that govern adaptation research; not to mention new methods and tools to support research. 


\section{Conclusions}

Research alone is not sufficient to drive adaptation responses within society [33].

However, research does have a role to play in generating useful knowledge when that research is aligned to the decision problems of those charged with planning and implementing adaptation. Achieving that alignment remains challenging as it effectively 284 forces the conventional research enterprise and individual researchers to adapt themselves. 285 That reflexive process has commenced, perhaps as part of a broader transformation in the 286 structure of social institutions. However, such transformations are disruptive. The significant, 287 non-academic work associated with problem-oriented, transdisciplinary adaptation research is 288 its key strength, yet it is one that is frequently under-acknowledged and under-valued. 289 Increasingly, individual researchers are expected to perform effectively in multiple roles, 290 some of which are incommensurate with their traditional disciplinary academic training. This 291 can ultimately weaken research efforts and their usefulness if not acknowledged in research 292 funding models. Augmenting disciplinary knowledge with expertise in communications, 293 facilitation, and policy development while cultivating boundary managers that can effectively 294 integrate these diverse skills could assist in the maturation of adaptation research. At the 295 same time, however, ongoing development of a third, more reflexive orientation for 296 adaptation research is needed that enhances understanding of the research enterprise itself and 297 how adapt to support the research required for adaptation more broadly. 


\section{Acknowledgements}

This manuscript has been authored in part by UT-Battelle, LLC under Contract No. DEAC05-00OR22725 with the U.S. Department of Energy. The United States Government retains and the publisher, by accepting the article for publication, acknowledges that the United States Government retains a non-exclusive, paid-up, irrevocable, world-wide license to publish or reproduce the published form of this manuscript, or allow others to do so, for United States Government purposes. The Department of Energy will provide public access to these results of federally sponsored research in accordance with the DOE Public Access Plan (http://energy.gov/downloads/doe-public-access-plan). In addition, many of the ideas presented in this paper were generated through the authors' experience with participatory research projects and stakeholder engagement activities supported by the Victorian Centre for Climate Change Adaptation Research, Australia.

\section{References}

1. Preston BL, Rickards L, Dessai S, Meyer R: Water, seas, and wine: Science for successful climate adaptation. In Successful Adaptation to Climate Change: Linking Science and Policy in a Rapidly Changing World. Edited by Moser S, Boycoff M: Routledge; 2013:151-169.

- Using three international case studies of efforts to use climate change and/or adaptation research to facilitate adaptation planning and implementation, the authors discuss the opportunities and challenges associated with the successful integration of research into adaptation responses.

\section{Swart R, Biesbroek R, Lourenço TC: Science of adaptation to climate change and science for adaptation. Interdisciplinary Climate Studies 2014, 2:29.}

- This paper discusses the bias in current adaptation research toward practice-oriented research in partnership with stakeholders, which, the authors note, has not necessarily generated a sound knowledge base to inform adaptation implementation. The authors therefore emphasise the importance of continuing to develop fundamental knowledge of adaptation based on disciplinary sciences.

3. Turner J: The Institutional Order. New York, New York, USA: Longman.; 1997.

4. Meyer R: The public values failures of climate science in the US. Minerva 2011, 49:4770.

5. Morecroft M, Crick H, Duffield S, Macgregor N, Taylor S: Enhancing the impact of climate science. Nature Climate Change 2014, 4:842-843.

6. Rose DC: Five ways to enhance the impact of climate science. Nature Climate Change 2014, 4:522-524.

7. Cash DW, Clark WC, Alcock F, Dickson NM, Eckley N, Guston DH, Jäger J, Mitchell RB: Knowledge systems for sustainable development. Proceedings of the National Academy of Sciences 2003, 100:8086-8091. 
8. Nyden P, Wiewel W: Collaborative research: harnessing the tensions between researcher and practitioner. The American Sociologist 1992, 23:43-55.

9. $\mathrm{P}$ B: Conceptual, theoretical and practical issues in measuring the benefits of public participation. Evaluation 2009, 15:263-284.

10. Burton P: Planning for climate change: is greater public participation the key to success? Urban Policy Research 2013, 31:399-415.

11. Black A: Extension theory and practice: a review. Animal Production Science 2000, 40:493-502.

12. Javeline D: The Most Important Topic Political Scientists Are Not Studying: Adapting to Climate Change. Perspectives on Politics 2014, 12:420-434.

13. Castree N, Adams WM, Barry J, Brockington D, Buscher B, Corbera E, Demeritt D, Duffy R, Felt U, Neves K, et al.: Changing the intellectual climate. Nature Climate Change 2014, 4:763-768.

-In this commenatry, the authors discuss the disconnect between the growing societal emphasis on integrated, problem-oriented science and the continued lack of emphasis on social science and humanities research. The authors therefore suggest the need for a richer conception of the role of science to address the challaenges of global change through broader intellectual engagement and dialogue among diverse stakeholders.

14. Westling EL, Sharp L, Rychlewski M, Carrozza C: Developing adaptive capacity through reflexivity: lessons from collaborative research with a UK water utility. Critical policy studies 2014, 8:427-446.

15. Gottschick M: Reflexive Capacity in Local Networks for Sustainable Development: Integrating Conflict and Understanding into a Multi-Level Perspective Transition Framework. Journal of Environmental Policy \& Planning 2013:1-22.

16. Beck S, Borie M, Chilvers J, Esguerra A, Heubach K, Hulme M, Lidskog R, Lövbrand E, Marquard $\mathrm{E}$, Miller $\mathrm{C}$ : Towards a reflexive turn in the governance of global environmental expertise. The cases of the IPCC and the IPBES. GAIA-Ecological Perspectives for Science and Society 2014, 23:80-87.

- This paper compares and contrasts two different approaches to international scientific assessment with a focus on the role of scientific expertise. The authors argue there is no single approach to assessment and therefore a reflexive approach is needed whereby the process and governance of each assessment should be negotiated de novo.

17. Schön DA: The Reflexive Practitioner: How Professionals Think in Action: Basic Books; 1983.

18. Cunliffe AL: On becoming a critically reflexive practitioner. Journal of Management Education 2002, 28:407-426.

19. Hajer M: Policy without polity. Policy Sciences 2003, 36:175-195.

20. Freshwater D, Fisher P: (Con) Fusing Commerce and Science Mixed Methods Research and the Production of Contextualized Knowledge. Journal of Mixed Methods Research 2014, 8:111-114.

21. Gibbons M, Limoges C, Nowotny H, Schwartzman S, Scott P, Trow M: The new production of knowledge: The dynamics of science and research in contemporary societies: Sage; 1994.

22. Gibbons M: Mode 2 society and the emergence of context-sensitive science. Science and Public Policy 2000, 27:159-163.

23. Neumann R, Guthrie J: The corporatization of research in Australian higher education. Critical Perspectives on Accounting 2002, 13:721-741. 
24. Nowotny H, Scott P, Gibbons M: Introduction:Mode 2'Revisited: The New Production of Knowledge. Minerva 2003, 41:179-194.

25. Besley JC, Tanner AH: What science communication scholars think about training scientists to communicate. Science Communication 2011, 33:239-263.

26. Bulkeley H: Governing climate change: the politics of risk society. Transactions of the Institute of British Geographers 2001, 26:430-447.

27. AGO: Climate Change Impacts \& Risk Management: A Guide for Business and Government. Canberra, Australia: Australian Greenhouse Office; 2006.

28. Beck U: Risk Society: Towards a New Modernity. London, UK: Sage; 1992.

29. Beck U, Giddens A, Lash S: Reflexive Modernization: Politics, Tradition, and Aesthetics in the Modern Social Order. Cambridge, UK: Polity Press; 1994.

30. Beck U, Bonss W: The Theory of Reflexive Modernization: Problematic, Hypotheses and Research Programme. Theory, Culture \& Society 2003, 20:1-33.

31. Measham T, Preston BL: Vulnerability analysis, risk and deliberation: The Sydney climate change adaptation initiative. In Risk and Social Theory in Environmental Management. CSIRO Publishing; 2012:147-157.

32. McCright AM, Dunlap RE: Anti-reflexivity The American conservative movement's success in undermining climate science and policy. Theory, Culture \& Society 2010, 27:100-133.

33. Klein RJT, Midgley GF, Preston BL, Alam M, Berkhout FGH, Dow K, Shaw MR: Adaptation opportunities, constraints, and limits. In Climate Change 2014: Impacts, Adaptation, and Vulnerability. Part A: Global and Sectoral Aspects. Contribution of Working Group II to the Fifth Assessment Report of the Intergovernmental Panel on Climate Change. Edited by Field CB, Barros VR, Dokken DJ, Mach KJ, Mastrandrea MD, Bilir TE, Chatterjee M, Ebi KL, Estrada YO, Genova RC, et al.: Cambridge University Press; 2014:in press.

34. Pidgeon N, Fischhoff B: The role of social and decision sciences in communicating uncertain climate risks. Nature Climate Change 2011, 1:35-41.

35. Tompkins EL, Adger WN, Boyd E, Nicholson-Cole S, Weatherhead K, Arnell N: Observed adaptation to climate change: UK evidence of transition to a welladapting society. Global Environmental Change 2010, 20:627-635.

36. Executive Office of the President: The President's Climate Action Plan. Washington, DC: Executive Office of the President; 2013.

37. Commonwealth of Australia: Climate Adaptation Outlook. Canberra: Department of Industry, Innovation, Climate Change, Science, Research, and Tertiary Education; 2013.

38. Pielke RAJ: The Honest Broker: Making Sense of Science in Policy and Politics. Cambridge, UK: Cambridge University Press; 2007.

39. Rickards L, Wiseman J, Kashima Y: Barriers to effective climate change mitigation: the case of senior government and business decision makers. Wiley Interdisciplinary Reviews: Climate Change 2014, 5:753-773.

40. Dow K, Berkhout F, Preston BL, Klein RJT, Midgley G, Shaw MR: Limits to adaptation. Nature Clim. Change 2013, 3:305-307.

41. van Buuren A, Eshius J, van Vliet M: Action Research for Climate Change Adaptation: Developing and Applying Knowledge for Governance. Abingdon, UK and New York, New York, USA: Routledge; 2014.

42. Pielke RA: Future economic damage from tropical cyclones: sensitivities to societal and climate changes. Philosophical Transactions of the Royal Society A: Mathematical, Physical and Engineering Sciences 2007, 365:2717-2729. 
43. Lemos MC, Kirchhoff CJ, Ramprasad V: Narrowing the climate information usability gap. Nature Climate Change 2012, 2:789-794.

44. Lemos MC: Usable climate knowledge for adaptive and co-managed water governance. Current Opinion in Environmental Sustainability 2015, 12:48-52.

- This paper investigates the production and use of climate knowledge for the governance of water resources. The authors argue that evidence of how science has contributed to adaptive capacity remains limited and greater focus needs to be directed toward actively managing the boundary between science and policy.

45. Adger WN, Dessai S, Goulden M, Hulme M, Lorenzoni I, Nelson DR, Naess LO, Wolf J, Wreford A: Are there social limits to adaptation to climate change? Climatic Change 2009, 93:335-354.

46. Lemos MC, Morehouse BJ: The co-production of science and policy in integrated climate assessments. Global Environmental Change 2005, 15:57-68.

47. Hoppe R, Wesselink A, Cairns R: Lost in the problem: the role of boundary organisations in the governance of climate change. Wiley Interdisciplinary Reviews: Climate Change 2013, 4:283-300.

-The authors review the role of boundary organizations in mediating between scientific and policy communities associated with climate change governance. They also articulate the the nature of different organizations and the criteria that influence their success at the boundary.

48. Guston DH: Boundary organizations in environmental policy and science: an introduction. Science, technology, and human values 2001:399-408.

49. Prescott CE, Weese K: Crossing the Divide: Engaging scientists and policy-makers in adapting forest management to climate change in British Columbia. The Forestry Chronicle 2014, 90:89-95.

50. Jasanoff S: Beyond epistemology: relativism and engagement in the politics of science. Social studies of science 1996, 26:393-418.

51. Pohl C, Hadorn GH: Methodological challenges in transdisciplinary research. Natures Sciences Sociétés 2008, 16:111-121.

52. Holm P, Goodsite ME, Cloetingh S, Agnoletti M, Moldan B, Lang DJ, Leemans R, Moeller JO, Buendía MP, Pohl W: Collaboration between the natural, social and human sciences in Global Change Research. Environmental Science \& Policy 2013, 28:25-35.

53. NSF: Proposal and Award Policies and Procedures Guide. Part I: Grant Proposal Guide. Arlington, VA, USA: National Science Foundation; 2014.

54. ARC: Research Impact Principles and Framework. Canberra, Australia: Australian Research Council; 2015.

55. Preston BL, Yuen EJ, Westaway RM: Putting vulnerability to climate change on the map: a review of approaches, benefits, and risks. Sustainability Science 2011, 6:177-202.

56. Preston BL: Climate Change Vulnerability Assessment: From Conceptual Frameworks to Practical Heuristics: CSIRO Climate Adaptation Flagship Working paper; 2012.

57. Mastrandrea MD, Heller NE, Root TL, Schneider SH: Bridging the gap: linking climate change impacts research with adaptation planning and management. Climatic Change 2010, 100:87-101.

58. Bisaro A, Swart R, Hinkel J: Frontiers of solution-oriented adaptation research. Regional Environmental Change 2015:1-14. 
-The authors synthesize findings regarding experinces reported in the literature with respect to the pursuit of solution-oriented adaptation research. They find that approaches to adaptation are heterogenous and the tools available through the social sciences are underutilized.

59. Vogel C, Moser SC, Kasperson RE, Dabelko GD: Linking vulnerability, adaptation, and resilience science to practice: Pathways, players, and partnerships. Global Environmental Change 2007, 17:349-364.

60. Wickson F, Carew AL, Russell A: Transdisciplinary research: characteristics, quandaries and quality. Futures 2006, 38:1046-1059.

61. Mobjörk M: Consulting versus participatory transdisciplinarity: A refined classification of transdisciplinary research. Futures 2010, 42:866-873.

62. Lyall C, Meagher L, Bruce A: A rose by any other name? Transdisciplinarity in the context of UK research policy. Futures 2014.

63. Homsy GC, Warner ME: Climate Change and the Co-Production of Knowledge and Policy in Rural USA Communities. Sociologia Ruralis 2013, 53:291-310.

64. Cornell S, Berkhout F, Tuinstra W, Tàbara JD, Jäger J, Chabay I, de Wit B, Langlais R, Mills D, Moll P: Opening up knowledge systems for better responses to global environmental change. Environmental Science \& Policy 2013, 28:60-70.

65. Weible CM, Heikkila T, deLeon P, Sabatier P: Understanding and influencing the policy process. Policy Sciences 2012, 45:1-21.

66. Preston BL, Keenan R: Research to Action: A Multi-Institutional Synthesis of the Victorian Centre for Climate Change Adaptation Research. Melbourne, Australia: Victorian Centre for Climate Change Adaptation Research; 2014.

67. Spruijt P, Knol AB, Vasileiadou E, Devilee J, Lebret E, Petersen AC: Roles of scientists as policy advisers on complex issues: a literature review. Environmental Science \& Policy 2014, 40:16-25.

-Based on an extensive review of literature addressing the role of experts in provisioning of policy advice, the authors find that experts acknowledge that they play multiple roles based on the problem, the values held by the expert, and the type of knowledge.

68. Rickards L: Report of the Melbourne Interdisciplinary Collaboration Exploration Project: Phase Two. Melbourne: Melbourne Research Office, University of Melbourne; 2014.

69. Jorgensen B, Merton E, Smith L, Wallis P: Faciliating the Use of Research in Policy Development and Implementation. Final Project Report. Melbourne: Victorian Centre for Climate Change Adaptation Research; 2014.

70. Lewis J: Funding social science research in academia. Social Policy \& Administration 2000, 34:365-376.

71. Preston B, Keenan R: Research to Action: A Multi-Institutional Synthesis of the Victorian Centre for Climate Change Adaptation Research. Melbourne: Victorian Centre for Climate Change Adaptation Research; 2014.

72. Ayre M, Nettle R: Doing integration in catchment management research: Insights into a dynamic learning process. Environmental Science \& Policy 2015, 47:18-31.

- This paper provides an empirical study of knowledge integration as a dynamic, practical and material process, challenging the idea of integrated knowledge as a good in itself or primarily cognitive. 
73. Wiek A, Ness B, Schweizer-Ries P, Brand FS, Farioli F: From complex systems analysis to transformational change: a comparative appraisal of sustainability science projects. Sustainability Science 2012, 7:5-24.

74. Hinkel J, Bisaro A: Methodological choices in solution-oriented adaptation research: a diagnostic framework. Regional Environmental Change 2014:1-14.

- Based on challenges encountered in interdisciplinary research on adaptation, and part of forthcoming UNEP guidance on adaptation, this paper proposes different research methodologies suitable for addressing different sorts of adaptation challenges.

\section{Hinkel J, Bisaro A: A review and classification of analytical methods for climate change adaptation. Wiley Interdisciplinary Reviews: Climate Change 2014, 6:171-} 188.

- This paper outlines how different analytical methods and disciplinary perspectives in adaptation research shape not only how adaptation is conceived, but also the type of social responses that research concludes is needed.

\section{Ravetz JR: Post-normal science and the complexity of transitions towards} sustainability. Ecological Complexity 2006, 3:275-284.

77. Bäckstrand K: Civic science for sustainability: reframing the role of experts, policymakers and citizens in environmental governance. Global Environmental Politics 2003, 3:24-41.

78. Wesselink A, Hoppe R: If post-normal science is the solution, what is the problem? The politics of activist environmental science. Science, Technology \& Human Values 2010:0162243910385786.

79. Funtowicz SO, Ravetz JR: Science for the post-normal age. Futures 1993, 25:739-755. 80. Simon D, Schiemer F: Crossing boundaries: complex systems, transdisciplinarity and applied impact agendas. Current Opinion in Environmental Sustainability 2015, 12:6-11.

- This paper discusses the challenges associated with achieving and demonstrating the practical impacts of transdisciplinary research in sustainability sciences. The authors note that successful applied research with impact requires ongoing enagement with stakeholders which is difficult to maintain. Hence, the evaluation of applied research efforts should be cognizant of the undertainties and challenges such research implies.

\section{Sandelowski M, Barroso J: Finding the findings in qualitative studies. Journal of} Nursing Scholarship 2002, 34:213-220.

82. McEvoy J: Multi- and interdisciplinary research - Problems of inititation, control, integration and reward. Policy Sciences 1972, 3:201-208.

83. Moss RH, Meehl GA, Lemos MC, Smith JB, Arnold JR, Arnott JC, Behar D, Brasseur GP, Broomell SB, Busalacchi AJ, et al.: Hell and High Water: Practice-Relevant Adaptation Science. Science 2013, 342:696-698.

- In this commentary, the authors make various recommendations to faciliate the integraiton of adaptation science into adaptation decision-making. In addition, two priority needs are identified: the development of institutions to enable adaptation science and increased financial investments in adaptation science. 
84. Fünfgeld H, Webb B, McEvoy D: The significance of adaptation framing in local and regional climate change adaptation initiatives in Australia. In Resilient Cities 2. Springer; 2012:283-293.

85. Fünfgeld H, McEvoy D: Frame divergence in climate change adaptation policy: insights from Australian local government planning. Environment and Planning C: Government and Policy 2014, 32:603-622.

-Based on several case studies of community-based adaptation research, this paper argues that different stakeholders in adaptation decision-making may adopt different framings of adaptation. This leads to inconsistencies in communication and in preferences for adaptation options. Hence, the authors recommend a more relfexive approach to framing adaptation and making those frames explicit.

86. Nalau J, Preston BL, Maloney MC: Is adaptation a local responsibility? Environmental Science \& Policy 2015, 48:89-98.

87. Preston BL, Mustelin J, Maloney MC: Climate adaptation heuristics and the science/policy divide. Mitigation and Adaptation Strategies for Global Change 2013:1-31.

88. Klein RJ, Juhola S: A framework for Nordic actor-oriented climate adaptation research. Environmental Science \& Policy 2014, 40:101-115.

-The authors examine a number of bottlnecks associated with the uptake of adaptation reseach in policy in the context of Nordic nations. In response, an actor-oriented approach to adaptation research is proposed to better align research investments with the decision context of adaptation practitioners.

89. Schipper L, Liu W, Krawanchid D, Chanthy S: Review of climate change adaptation methods and tools. Vientiane, Vietnam: Mekong River Commission; 2010.

90. Wilby RL, Troni J, Biot Y, Tedd L, Hewitson BC, Smith DM, Sutton RT: A review of climate risk information for adaptation and development planning. International Journal of Climatology 2009, 29:1193-1215.

91. Hinkel J: Indicators of vulnerability and adaptive capacity: Towards a clarification of the science-policy interface. Global Environmental Change 2011, 21:198-208.

92. Moser S: Why we need to do better on adaptation indicators. In SciDev.Net. Available at http://www.scidev.net/global/climate-change/opinion/better-climate-changeadaptation-indicators.html, accessed 14 April, 2015.

93. Chambwera M, Heal G, Dubeux C, Hallegatte S, Leclerc L, Markandya A, McCarl BA, Mechler R, Neumann JE: Economics of adaptation. In Climate Change 2014: Impacts, Adaptation, and Vulnerability. Part A: Global and Sectoral Aspects. Contribution of Working Group II to the Fifth Assessment Report of the Intergovernmental Panel of Climate Change. Edited by Field CB, Barros VR, Dokken DJ, Mach KJ, Mastrandrea MD, Bilir TE, Chatterjee M, Ebi KL, Estrada YO, Genova RC, et al.: Cambridge University Press; 2014:945-977.

94. Barnett J, O’Neill S: Maladaptation. Global Environmental Change 2010, 20 211-213. 95. Barnett J, O’Neill S, Waller S, Rogers S: Reducing the risk of maladaptation in response to sea-level rise and urban water scarcity. Successful Adaptation to Climate Change: Linking Science and Policy in a Rapidly Changing World 2013:3749.

96. Thomsen DC, Smith TF, Keys N: Adaptation or manipulation? Unpacking climate change response strategies. Ecology and Society 2012, 17:20. 
97. Lennox J, Proctor W, Russell S: Structuring stakeholder participation in New Zealand's water resource governance. Ecological economics 2011, 70:1381-1394.

98. Few R, Brown K, Tompkins EL: Public participation and climate change adaptation: avoiding the illusion of inclusion. Climate Policy 2007, 7:46-59.

99. van Aalst MK, Cannon T, Burton I: Community level adaptation to climate change: The potential role of participatory community risk assessment. Global Environmental Change 2008, 18:165-179.

100. Lacey J, Howden SM, Cvitanovic C, Dowd A-M: Informed adaptation: ethical considerations for adaptation researchers and decision-makers. Global Environmental Change 2015, in press.

-This paper explores the ethical dimensions of adaptation research and the ethical responsibilites of adaptation researchers. Using agricultural adaptation as a case study, the authors identify the need for greater clarity in the articulation of adaptation research and practice and careful consideration of how stakeholder engagement is used in research.

101. Nordhagen S, Calverley D, Foulds C, Thom LL, Wang X: Credibility in Climate Change Research: A Reflexive View. Cambridge, Manchester, and Norwich, UK: Tyndall Centre for Climate Change Research; 2012. [Research TCfCC (Series Editor):

102. Preston BL, Westaway RM, Yuen EJ: Climate adaptation planning in practice: an evaluation of adaptation plans from three developed nations. Mitigation and Adaptation Strategies For Global Change 2011, 16:407-438.

103. Bierbaum R, Smith J, Lee A, Blair M, Carter L, Chapin FS, III, Fleming P, Ruffo S, Stults M, McNeeley $S$, et al.: A comprehensive review of climate adaptation in the United States: more than before, but less than needed. Mitigation and Adaptation Strategies for Global Change 2013, 18:361-406.

104. Eakin HC, Patt A: Are adaptation studies effective, and what can enhance their practical impact? Wiley Interdisciplinary Reviews: Climate Change 2011, 2:141153.

105. Goring SJ, Weathers KC, Dodds WK, Soranno PA, Sweet LC, Cheruvelil KS, Kominoski JS, Rüegg J, Thorn AM, Utz RM: Improving the culture of interdisciplinary collaboration in ecology by expanding measures of success. Frontiers in Ecology and the Environment 2014, 12:39-47.

- Examining the costs and benefits of interdisciplinary collaboration, this paper discusses the challenges traditional academic measures of success pose for researchers, particularly those early in their careers. The authors suggest the by promoting alternative measures of research success can enhance incentives and rewards for interdisciplinary research.

106. Preston BL, Kay RC: Managing climate risk in human settlements. In Greenhouse 2009. Edited by Jubb I, Holber P, Cai W: CSIRO Publishing; 2010:185-196.

107. Juhola S, Peltonen L, Niemi P: The ability of Nordic countries to adapt to climate change: assessing adaptive capacity at the regional level. Local Environment 2012, 17:717-734.

108. Green D, Niall S, Morrison J: Bridging the gap between theory and practice in climate change vulnerability assessments for remote Indigenous communities in northern Australia. Local Environment 2012, 17:295-315.

109. Spence A, Poortinga W, Pidgeon N: The Psychological Distance of Climate Change. Risk Analysis 2012, 32:957-972. 
659

660

661

662

663

664

665

666

110. Wong-Parodi G, Fischhoff B, Strauss B: A method to evaluate the usability of interactive climate change impact decision aids. Climatic Change 2014, 126:485493

111. Seidl R, Lexer MJ: Forest management under climatic and social uncertainty: trade-offs between reducing climate change impacts and fostering adaptive capacity. Journal of environmental management 2013, 114:461-469. 
667 Table 1. Examples of reflexive research findings within the climate adaptation literature.

\begin{tabular}{|c|c|c|}
\hline $\begin{array}{c}\text { Categories of } \\
\text { Reflexive Research }\end{array}$ & Examples of Reflexive Research Findings & References \\
\hline \multirow{2}{*}{$\begin{array}{l}\text { Institutionalization } \\
\text { of Adaptation } \\
\text { Research }\end{array}$} & $\begin{array}{l}\text { There is a need for institutional structures to } \\
\text { support adaptation research for enhanced } \\
\text { climate preparedness }\end{array}$ & {$[66,83]$} \\
\hline & $\begin{array}{l}\text { Demands for adaptation knowledge are driving } \\
\text { the development of new boundary spanning } \\
\text { organizations }\end{array}$ & {$[1]$} \\
\hline \multirow{3}{*}{$\begin{array}{l}\text { Adaptation } \\
\text { Framing }\end{array}$} & $\begin{array}{l}\text { Cognitive biases of researchers and } \\
\text { practitioners influence the framing of } \\
\text { adaptation and policy preferences }\end{array}$ & [84-87] \\
\hline & $\begin{array}{l}\text { Top-down scenario-driven approaches to } \\
\text { adaptation assessment neglect local context } \\
\text { that shapes the development of adaptation } \\
\text { responses }\end{array}$ & {$[57]$} \\
\hline & $\begin{array}{l}\text { Failure to consider agency and the role of } \\
\text { actors in adaptation reduces the effectiveness } \\
\text { of adaptation processes }\end{array}$ & {$[57,88]$} \\
\hline \multirow{3}{*}{$\begin{array}{l}\text { Adaptation } \\
\text { Planning }\end{array}$} & $\begin{array}{l}\text { - Adaptation planning processes are } \\
\text { underdeveloped and poorly integrated into } \\
\text { other planning and policy instruments }\end{array}$ & {$[102,103]$} \\
\hline & $\begin{array}{l}\text { Limited understanding of which adaptation } \\
\text { methods and tools are appropriate for different } \\
\text { contexts limits their effective application }\end{array}$ & {$[74,88,89]$} \\
\hline & $\begin{array}{l}\text { There is a need for greater attention to climate } \\
\text { change consequences and adaptation over } \\
\text { near-term time horizons }\end{array}$ & {$[90]$} \\
\hline \multirow{3}{*}{$\begin{array}{l}\text { Analytic Tools and } \\
\text { Metrics }\end{array}$} & $\begin{array}{l}\text { - Criteria and metrics for monitoring and } \\
\text { evaluating adaptation and its success are } \\
\text { lacking }\end{array}$ & {$[55,56,92,104,105]$} \\
\hline & $\begin{array}{l}\text { Metrics of vulnerability and adaptive capacity } \\
\text { can generate spurious perceptions of } \\
\text { adaptation needs }\end{array}$ & {$[55,91,106,107]$} \\
\hline & $\begin{array}{l}\text { Disconnects exist between the spatial and } \\
\text { temporal scale of analyses, data, and } \\
\text { information generated by research and that } \\
\text { needed by stakeholders for operational } \\
\text { decision-making }\end{array}$ & {$[57,88,108-110]$} \\
\hline \multirow{3}{*}{$\begin{array}{l}\text { Inefficiencies, } \\
\text { Externalities and } \\
\text { Trade-offs }\end{array}$} & $\begin{array}{l}\text { - Adaptation is unlikely to eliminate climate risk } \\
\text { and its implementation may be less than } \\
\text { optimal }\end{array}$ & {$[33,93]$} \\
\hline & - Adaptation actions can be maladaptive & [94-96] \\
\hline & $\begin{array}{l}\text { - Adaptation options may be associated with } \\
\text { real or perceived trade-offs with respect to } \\
\text { other objectives }\end{array}$ & {$[33,111]$} \\
\hline
\end{tabular}


- Stakeholder participation can assist in the assessment of vulnerability and risk and in the design and implementation of adaptation

\section{Stakeholder Engagement and} Participation 668
Adaptation Research Ethics

- It cannot be assumed that participation necessarily results in better adaptation $[9,10,87,98]$ planning or policy outcomes

- There is a need for greater consideration of ethics in research practice in order to better support alignment of adaptation research public values

- The personal, professional, and public actions of researchers all have the power to influence the perceived credibility of research 
1

2

3671

4

672 Figure 1. Annual number of peer-reviewed publications published between 1990 and 2013.

673 Publications were identified based on a key word search of the Web of Science database

674 (accessed October 29, 2014) using the terms "climate" and "adaptation". 


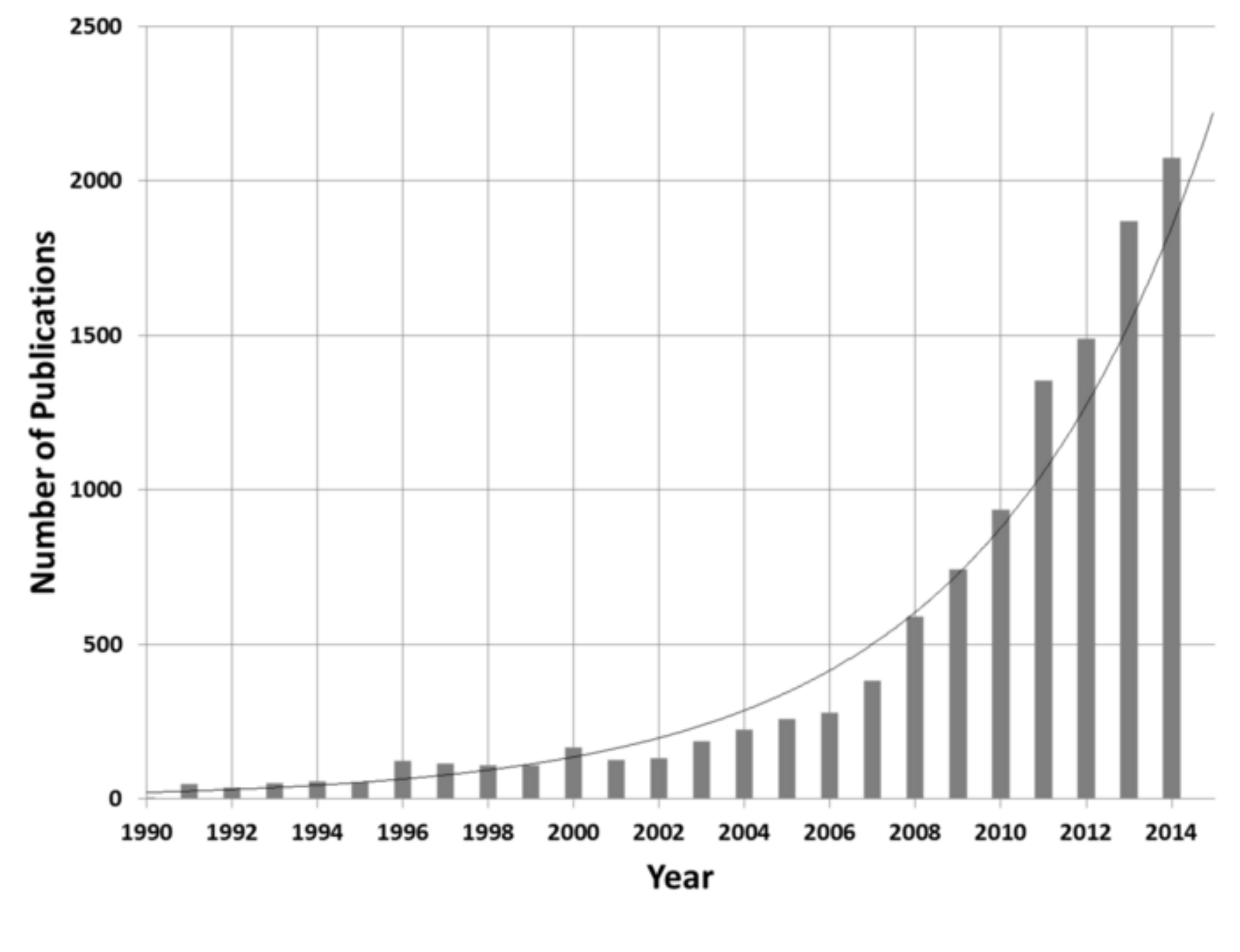

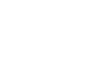

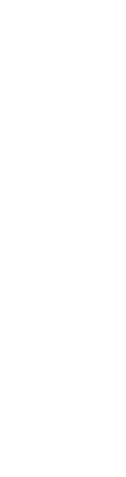

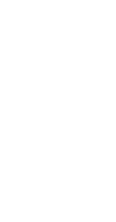

